\title{
NOTE ON ORTHOGRAPHY
}

Yoruba is a tonal language, with three underlying pitch levels for vowels and syllabic nasals: low tone (indicated with a grave accent: kò, 'n), mid tone (not marked: le, n) and high tone (indicated with an acute accent: wí, 'n). Speech is characterised by continual glides between these levels.

The orthography adopted in this book is the modern standard style recommended by the Yoruba Orthography Committee. The following symbols are employed:

e roughly as in English 'get' (cf. e as in French 'chez')

o roughly as in English 'pot' (cf. o as in French 'eau')

$\mathbf{s}$ the sound written in English as sh

$\mathbf{p}$ the voiceless labio-velar sound $k p$ where $k$ and $p$ are simultaneously pronounced.

Poetic texts in Yoruba are written with full tone markings. Lineation is partly subjective, but is based on a combination of the performer's breathpauses and the linguistic structure of the text. Where the texts reveal features of the Ossun area dialect, these have been preserved, e.g. Enikoyi [for standard Yoruba Onikoyi], șègi [for standard Yoruba sègi], mid-tone third person possessive re [for standard Yoruba low-tone rè].

When Yoruba sentences or phrases are quoted in passing, they are italicised and tone-marked. However, isolated Yoruba words are not tonemarked, because the frequency of their occurrence would cause problems for the typesetters. For reference, all such words are listed with full tone marks in the glossary. The word 'oba' (king) is not italicised because it is used in English constructions such as oba's, obas, ọbaship. 


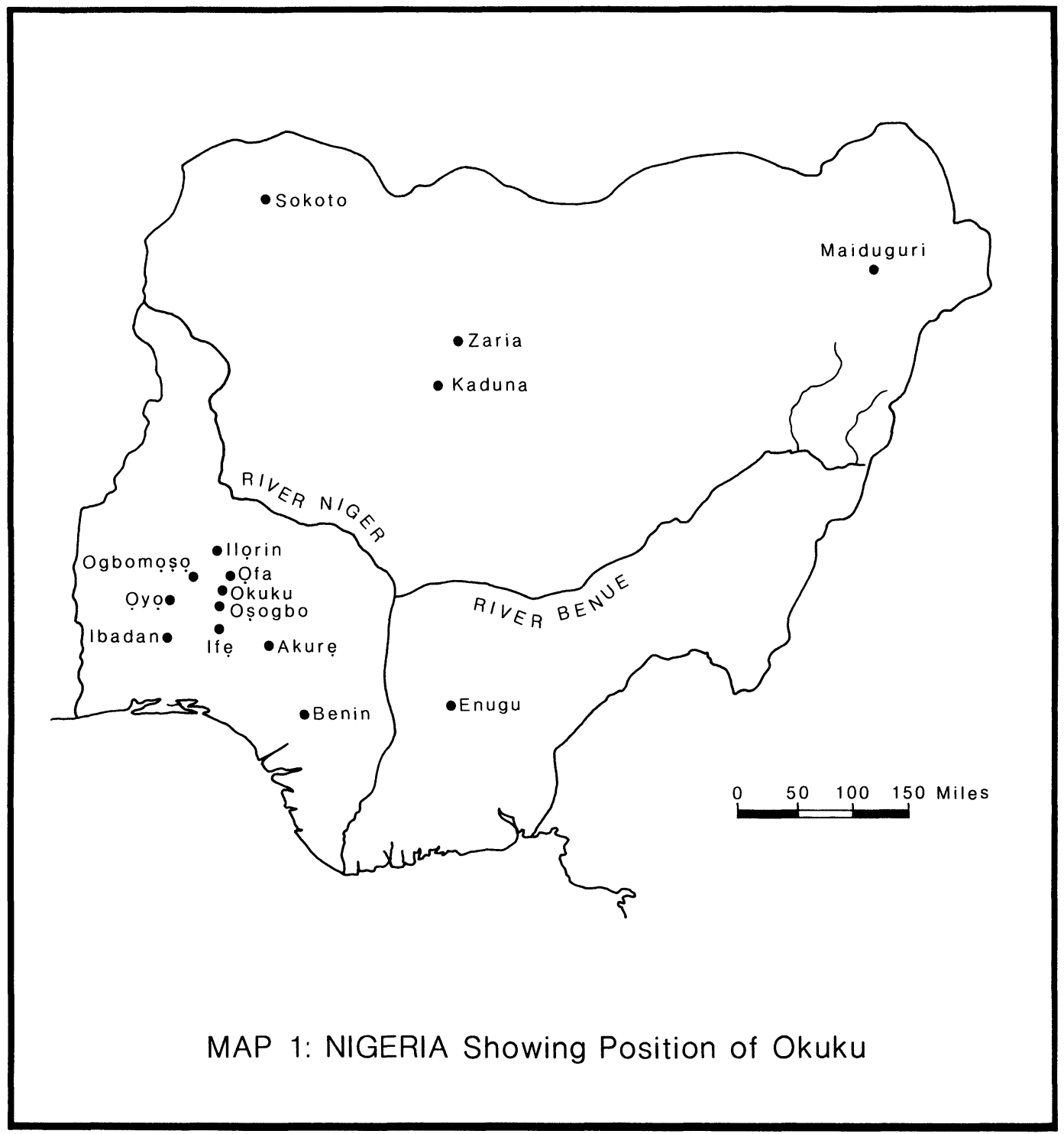


